\title{
A Global Statement for Air Pollution and Health
}

\author{
Caradee Y. Wright ${ }^{*}{ }^{*}, 2$, Danielle A. Millar(이 ${ }^{1}$ \\ ${ }^{1}$ South African Medical Research Council, Environment and Health Research Unit, 1 Soutpansberg Rd, Pretoria, Gauteng, South Africa \\ ${ }^{2}$ University of Pretoria, Department of Geography, Geoinformatics and Meteorology, cnr Lynnwood Road and Roper Street, Pretoria, \\ Gauteng, South Africa \\ *cwright@mrc.ac.za
}

https://doi.org/10.17159/caj/2019/29/2.7636

\section{Statement}

The Statement is available at:

https://air-pollution.health

\section{Keywords}

Air pollution, human health, wellbeing, climate change, environmental health
Air pollution poses a major threat to human health. It is estimated that $91 \%$ of the world's people live in places that did not meet the air quality guidelines of the World Health Organization (WHO, 2019a). Exposure to air pollution is well-established to be associated with adverse health effects, including respiratory conditions, either exacerbating existing diseases or increasing susceptibility to respiratory and other infections (WHO, 2019b). Currently many areas in South Africa exceed National Ambient Air Quality Standards. Priority Areas of air pollution hotspots are being managed to try to improve air quality (SA DEA, 2019).

In July 2019, at the United Nations headquarters in New York, the Academy of Sciences of South Africa (ASSAf) joined the science academies of Germany, Brazil, and the United States, as well as the US National Academy of Medicine, in issuing an urgent call to citizens, governments, and businesses to reduce global air pollution. The delegation presented a science-policy statement to senior United Nations representatives and highlevel diplomats. ASSAf was represented at the event by Executive Officer, Professor Himla Soodyall, and was joined by Senior Specialist Scientist in the Environment and Health Research Unit of the South African Medical Research Council (SAMRC) Dr Caradee Wright. Dr Jacqueline McGlade, former Chief Scientist to the United Nations, led the scientific delegation (Figure 1).

National Academies are a forum in which scientists from all disciplines come together. This creates a unique position to address pressing issues; in this case, air pollution and health, to lobby that air pollution is moved up the policy agenda. The statement appeals for emissions controls in all countries as well as proper monitoring of key pollutants, especially $\mathrm{PM}_{25}$, and stresses that funding is needed to invest in air pollution reduction measures to mirror the scale of the problem. Decisive action by stakeholders in all sectors would culminate in costeffective management of air pollution.

The success and urgency with which this initiative will be met relies on an increase in international stakeholders therefore, including the public, policy makers, and researchers. September 2019 saw national action being taken. Approximately 200 delegates from the Environmental Health fraternity attended

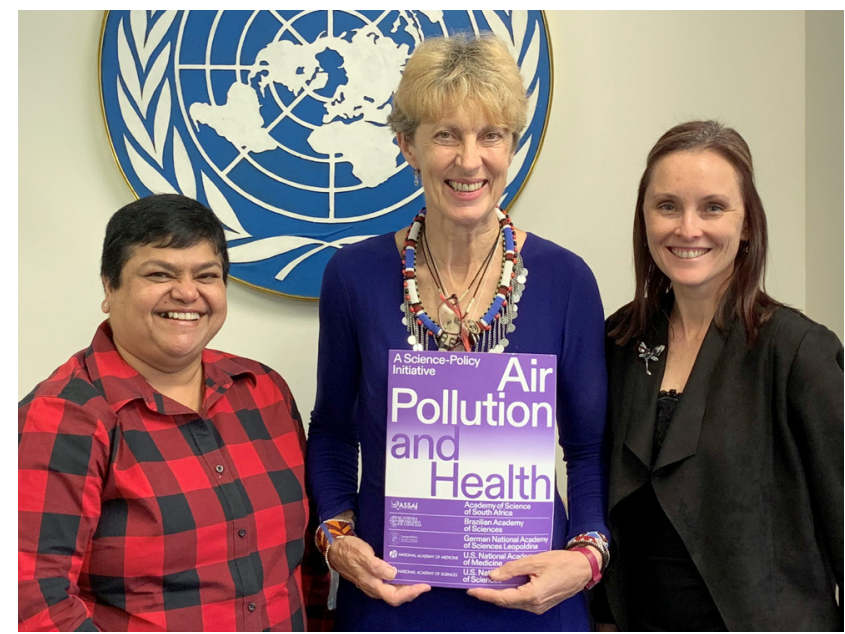

Prof Soodyall, Dr McGlade and Dr Wright in NYC, June 2019.

a two-day conference celebrating World Environmental Health Day 2019. A WHO-facilitated dialogue on air pollution and health was held and several actions were proposed which the National Department of Health committed to pursue in the coming months.

\section{References}

WHO, 2019a. Ambient air pollution [Internet]. World Health Organization. 2019 [cited 31 July 2019]. Available from: https:// www.who.int/airpollution/ambient/en/

WHO, 2019b. Ambient (outdoor) air quality and health [Internet]. Who.int. 2019 [cited 31 July 2019]. Available from: https://www. who.int/en/news-room/fact-sheets/detail/ambient-(outdoor)air-quality-and-health

South Africa: Department of Environmental Affairs, 2019. Air quality [Internet]. [cited 31 July 2019]. Available from: https://www.environment.gov.za/sites/default/files/reports/ environmentoutlook_chapter10.pdf 